\title{
THE HEART IN HÆMOCHROMATOSIS
}

\author{
BY \\ W. G. A. SWAN AND H. A. DEWAR
}

From the Regional Cardiovascular Department and the Royal Victoria Infirmary, Newcastle upon Tyne

Received December 10, 1950

The purpose of this paper is to give a brief account of present-day knowledge of the effects of hæmochromatosis upon the heart after which we shall describe two cases of the disease in which cardiac involvement was a prominent feature stimulating our interest in this subject. The involvement of the heart in hæmochromatosis is well known. Infiltration of hæmosiderin varies from wedge-shaped deposits at the nuclear poles of the muscle fibres to the extreme degree in which the fibres may be replaced by a mass of pigment granules contained within the muscle sheath. Hæmosiderin may also be found in the connective tissue, lying free in the lymph spaces, or within fibroblasts and mononuclear cells. An increase of fibrous tissue has been considered to be rare. Hæmofuscin is also found in the muscle fibres arranged in the same way as hæmosiderin (Sheldon, 1935).

In his review of 311 cases of hæmochromatosis Sheldon states that myocardial failure is uncommon and he places it as the cause of death in a miscellaneous group (15 per cent of 119 cases in which the cause of death was evident) which includes various intercurrent conditions. Within the past seventeen years a number of reports have appeared of cases of hæmochromatosis in which cardiac symptoms followed by death in congestive heart failure have occurred. We have selected ten reports comprising fourteen cases which are arranged in Table I. It is a pity that the pathological data are often very meagre. Significant coronary sclerosis or valvular lesions were not described except in the case of Blumer and Nesbit (1938) in which there was a moderate degree of coronary atheroma.

- Cardiac enlargement was noted in eleven cases, in four on clinical grounds only and in the remainder on radiography or necropsy or both.

Electrocardiographic findings are given for twelve cases. Four were normal, one after having shown $\mathrm{T}$ wave changes. Three showed low voltage; seven showed $\mathrm{T}$ wave changes other than in lead III; there were three examples of auricular fibrillation and one of auricular flutter; there was one paroxysm of supraventricular tachycardia. There were two cases of complete heart block and one of prolonged P-R interval.

Substernal pain is mentioned in five cases. In two it was severe and in one it was often related to exertion. In one case, pain over a period of three weeks occurred three years before his death in heart failure. Necropsy in two instances showed myocardial fibrosis but there was coronary disease in only one (Blumer and Nesbit, 1938) and it was not severe. No myocardial infarction was found in any case.

Congestive heart failure closed the illness in all the fatal cases.

On the subject of the heart in hæmochromatosis, there have been a number of reports by French authors who have striven to invoke an endocrine origin for the observed heart failure without satisfying the reader or, apparently, themselves. The clinical reports describe cases that are comparable with the present series and doubtless represent the same disease process (de Gennes et al., 1936; Oumansky and Longuet, 1938). 


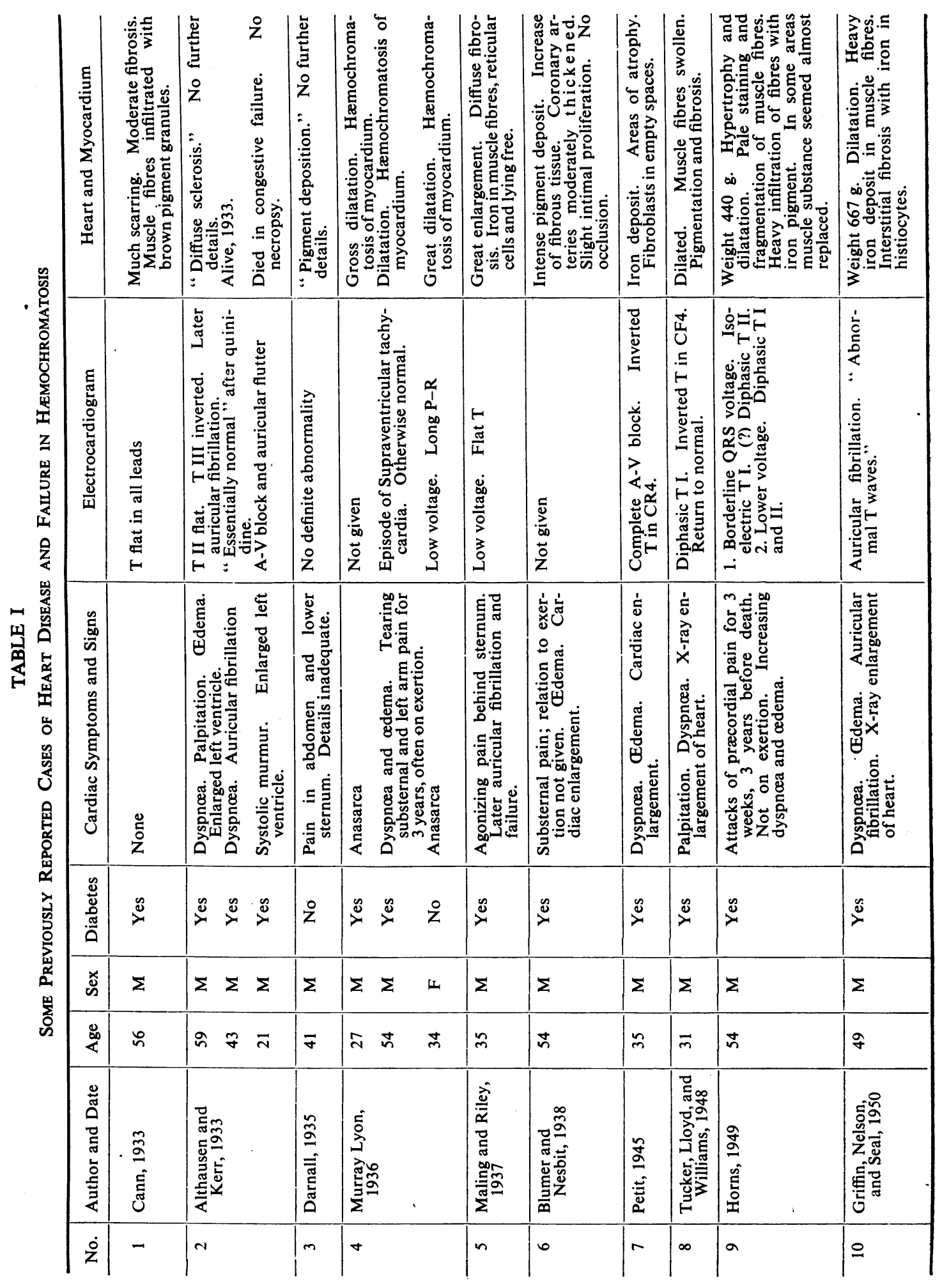




\section{CASE RePORTS}

Case 1. Man, aged 32. Buyer for National Coal Board. Subject to asthma from childhood. No other serious illness and not short of breath between attacks of asthma. In 1941 his family commented upon his dark skin; he did not think that the colour had darkened much since then. In 1946 he had two attacks of retrosternal and left-arm pain. After these he was seen by one of us (W.G.A.S.) for the Ministry of Pensions when a dusky colour. was noted and the liver and spleen were found to be enlarged. The blood pressure then was 130/85 and the heart was normal on clinical and radiological examination. An electrocardiogram then showed normal voltage and an upright T in I, II, III, and CR4.

After this he remained well until April, 1950, when, while sitting, he experienced severe pain starting at the lower end of the sternum and passing up into the neck and jaws but not down the arms. There was also sharp pain in the right side which caught his breath. He became breathless and sweated. The pain lasted eight hours. One week later he was wakened by exactly the same

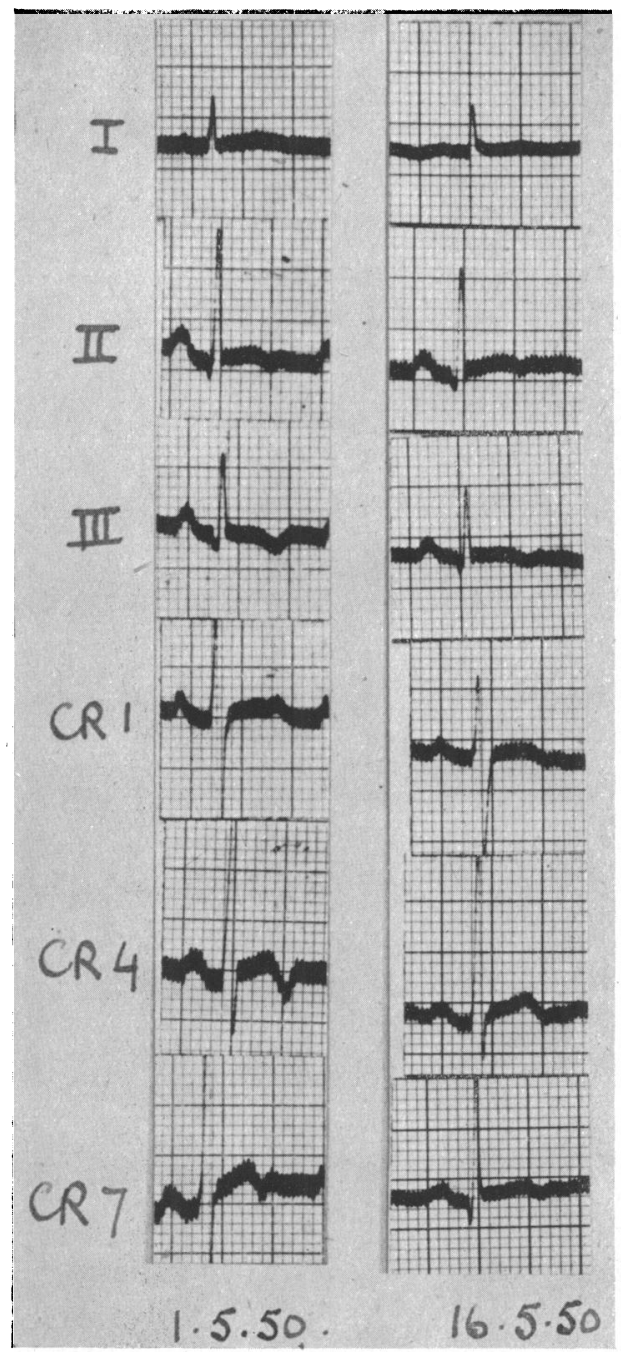

Fig. 1.-Case 1. Electrocardiograms showing $\mathrm{S}-\mathrm{T}$ and $\mathrm{T}$ wave changes. pain which lasted four hours. Again, one week later, a severe attack of the same pain woke him at night. This lasted for ten hours and left an ache which persisted until the next day, May 1, 1950, when he was admitted to hospital. He stated that he was not losing weight, had no excessive thirst and had not lost libido. He denied alcoholic excess. He shaved daily.

On admission he was noted to have uniform dark pigmentation of the skin over the whole body. The colour could best be called a leaden brown. The skin was fine and soft; there was no axillary hair and the pubic hair was scanty. His build was slender. The testes were not atrophied. There were no clinical signs of heart failure. The pulse was 90 and regular, and the blood pressure was $110 / 70$.

The heart and lungs were normal clinically. The liver was enlarged four finger breadths, was very firm but not tender: The spleen was palpable on inspiration. The urine was free from sugar, acetone, and albumen.

Half-hourly sugar tolerance test. $0 \cdot 132,0 \cdot 225,0 \cdot 290$, $0 \cdot 230,0 \cdot 175 \mathrm{mg}$. per $100 \mathrm{ml}$. No glycosuria.

Shin biopsy. There was iron-containing pigment immediately beneath the epidermis. It was mostly extra-cellular and some was in close apposition to the sweat glands.

Teleradiogram and fluoroscopy. Normal heart shadow. Normal lung fields.

Serial electrocardiograms (Fig. 1). Normal QRS voltage. S-T elevation and inversion of $\mathrm{T}$ in II, III, CR 4, and CR 7. T I almost iso-electric.

Progress. He had no further pain and he remains well at the time of writing. The electrocardiogram is changing slightly towards a more normal pattern.

Case 2. Man, aged 51. Coal miner. He was admitted to hospital on January 7,1948 , with a history that except for a hæmoptysis one year ago he had always 
been healthy until six weeks before admission when he rather rapidly developed dyspnoa on exertion and swelling of the legs. Later he was breathless even at rest, especially at night. Soon after this thirst and polyuria appeared and he lost flesh rapidly, but the odema went away.

On admission he was not in congestive failure but he looked thin and dehydrated. His lips were slightly cyanosed but neither skin nor mucous membranes were pigmented. The face, however, was strikingly smooth and he disclosed that for some years he had only needed to shave twice or thrice a week. Hair was absent from the axillæ and pubes and the penis was small. The left testis lay in the inguinal canal and the right, which lay in the scrotum, was obviously atrophied. The liver was enlarged two finger breadths below the costal margin and the spleen rather less; both were very firm. The urine contained sugar and acetone but no albumen.

Half-hourly sugar tolerance test. $0.22,0.29,0.40,0.42,0.40 \mathrm{mg}$. per $100 \mathrm{ml}$. No glycosuria except for a trace in the last sample.

Liver function tests. Thymol turbidity: 1 unit. Flocculation: 0 units. Alkaline phosphatase (Jenner and Kay): 9.2 units. Plasma proteins: 5.55 per cent; albumen, 4.08 per cent; globulin (by difference), 1.47 per cent. Hippuric acid excretion: $4 \mathrm{~g}$. sodium benzoate ingested, $2.71 \mathrm{~g}$. hippuric acid excreted (normal $3 \cdot 2$ g.).

Biopsy of liver: This showed essentially the appearances of a cirrhosis. The liver cells were stuffed with a pigment that gave a positive iron reaction-hæmosiderin. The appearances were compatible with the diagnosis of cirrhosis in a case of hæmochromatosis (Fig. 2).

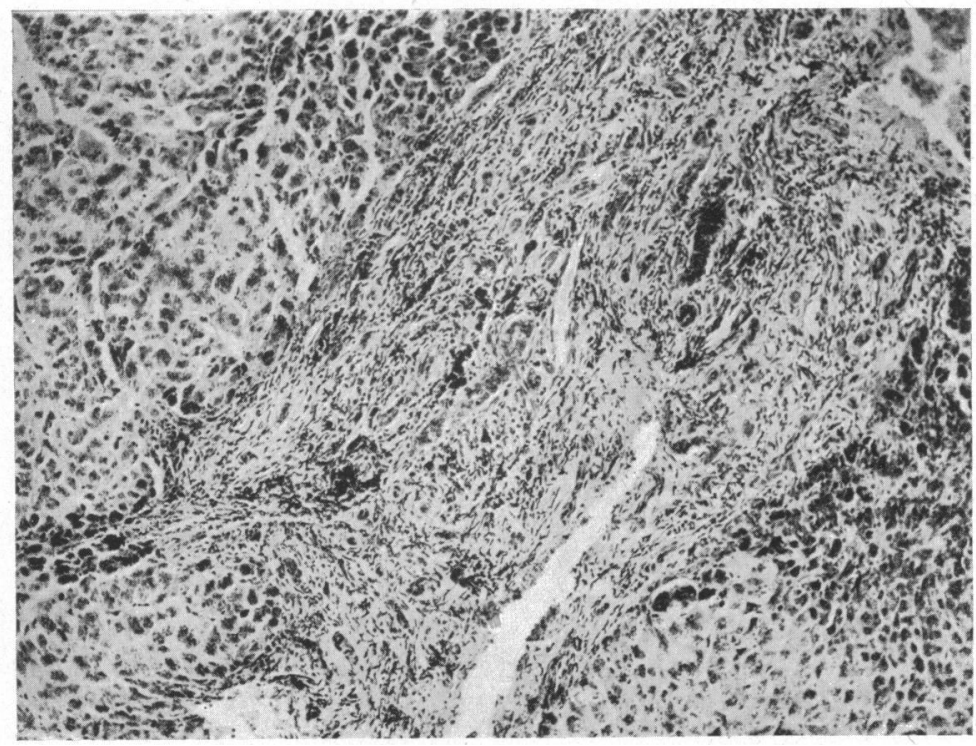

Fig. 2.-Case 2. Biopsy of liver, $\times 90$. Stained for iron.

X-Ray of chest: No active lung lesion; calcified focus in right lower zone. Blood count: hæmoglobin 92 per cent; white cells 13,600 per c.mm. Basal metabolic rate: +18 per cent. Excretion of 17-ketosteroids: $2 \mathrm{mg}$. in 24 hours. Plasma sodium: $330 \mathrm{mg}$. per $100 \mathrm{ml}$. Kepler test: index 12.

He was stabilized on $160 \mathrm{~g}$. carbohydrate with 10 and later 5 units of insulin twice daily. While in hospital his blood pressure fell and he developed congestive heart failure which improved with digitalis and mercurial diuretics so that he was discharged home eight weeks after admission. At home he gradually began to get about but after a few weeks dyspnœa increased and he was re- 
admitted to hospital in congestive failure only two months after he had left. This time he did not improve and he developed lobar pneumonia. He recovered from this infection after treatment with penicillin but succumbed to heart failure three weeks after admission.

Cardiovascular features. At his first admission, although there were symptoms of cardiac insufficiency, he had no congestive failure. His pulse rate was 78 a minute and his blood pressure 120/80. Cardioscopy revealed some slight enlargement of the left ventricle but no other abnormality. The rhythm, however, was persistently irregular and a cardiogram (Fig. 3) showed this to be due to frequent extrasystoles, most of which arose from varying auricular foci, some from

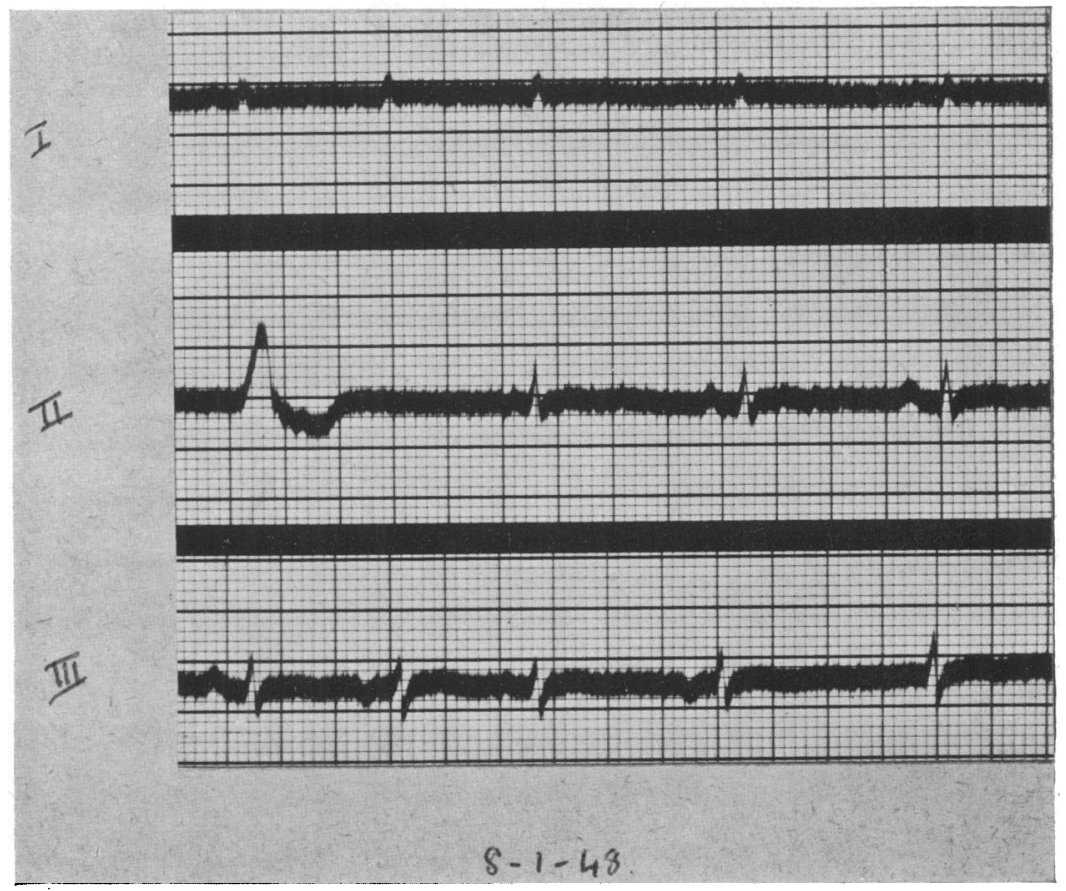

Fig. 3.-Case 2. Electrocardiogram showing low voltage QRS-T complexes and auricular and ventricular ectopic beats.

a ventricle. They continued with occasional intermissions until his death. This cardiogram showed also a very low voltage with slight elevation of S-T and flat T waves. CR leads taken one week later showed rounded elevation of S-T, maximal in CR 3 and 4, with sharp coronary type inversion of T in CR 4 to 6 (Fig. 4).

One week after admission the resting blood pressure had fallen to $82 / 70$ and thereafter until his death the systolic pressure always lay between 95 and 75 and the diastolic between 80 and 66 . On one occasion when the patient was stood up the systolic level rose to 95 . Congestive failure gradually increased, the heart became moderately dilated and a soft systolic murmur appeared at the apex. The heart rate ranged from 80 to 90 a minute but decreased after digitalization to between 50 and 60 . Fluids and salt were restricted and mercurial diuretics given. He improved on this regime and was free from odema when discharged home, still on digitalis.

When re-admitted he was much more severely dyspnœic and more cyanosed. The neck veins showed mild engorgement and postural œedema was extensive. The heart was now very greatly dilated, its apex lying in the sixth space almost in the anterior axillary line. The rhythm was still predominantly irregular, the blood pressure was $95 / 70$ and the rate 86 a minute. The 
cardiogram (Fig. 5) was essentially the same but the voltage was lower than ever. Lobar pneumonia developed and he died in persisting congestive heart failure sixteen days after admission.

Necropsy (Dr. Ian Rannie). The liver weighed $2350 \mathrm{~g}$. and showed moderate to severe cirrhosis with marked siderosis. The spleen contained practically no iron. The pancreas showed fibrosis

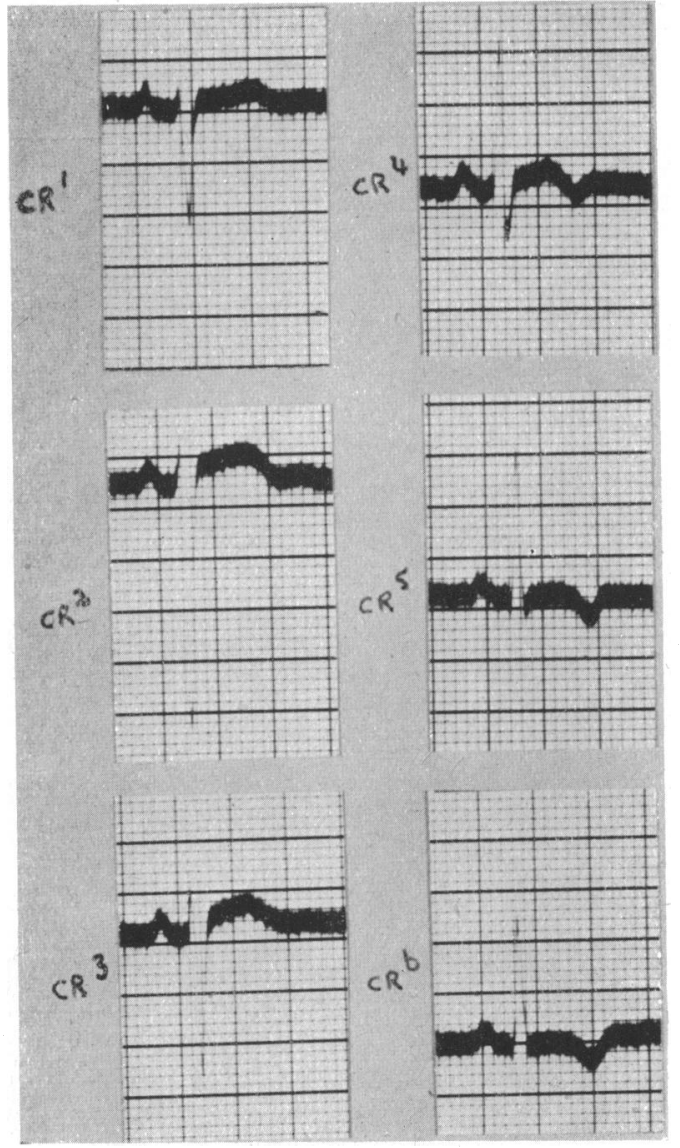

Fig. 4.-Case 2(15/1/48). CR leads showing S-T and $\mathrm{T}$ wave changes.

and had iron in both acinar and islet tissue. The skin showed only slight iron pigment around the sweat glands. The testes were completely atrophied. The pituitary showed marked siderosis and a large scar from healed necrosis affecting the major part of one half of the anterior lobe but much glandular tissue remained. The adrenals showed reduction of cortex without much lipoid and with iron pigment, mainly in the outer part. The heart weighed $400 \mathrm{~g}$. All the valves were healthy. Both auricles were dilated and both ventricles very greatly so. The myocardium measured $0.4 \mathrm{~cm}$. at the base of the right ventricle and $1.2 \mathrm{~cm}$. at the base of the left. The coronary arteries appeared to be healthy. There was an oval endocardial thickening measuring $1 \times 0.5 \mathrm{~cm}$. on the interventricular septum.

On histological examination the myocardium showed a patchy siderosis, the iron pigment being present in the form of granules in the myocardial fibres. There was considerable destruction of muscle with replacement fibrosis and it was noted that this fibrosis was most marked in those areas 
where the pigmentation of the muscle was most intense. Occasionally the pigment was seen to be in phagocytes in the interstitial tissue of the fibrotic areas but for the most part it was contained in the muscle cells themselves (Fig. 6 and 7).

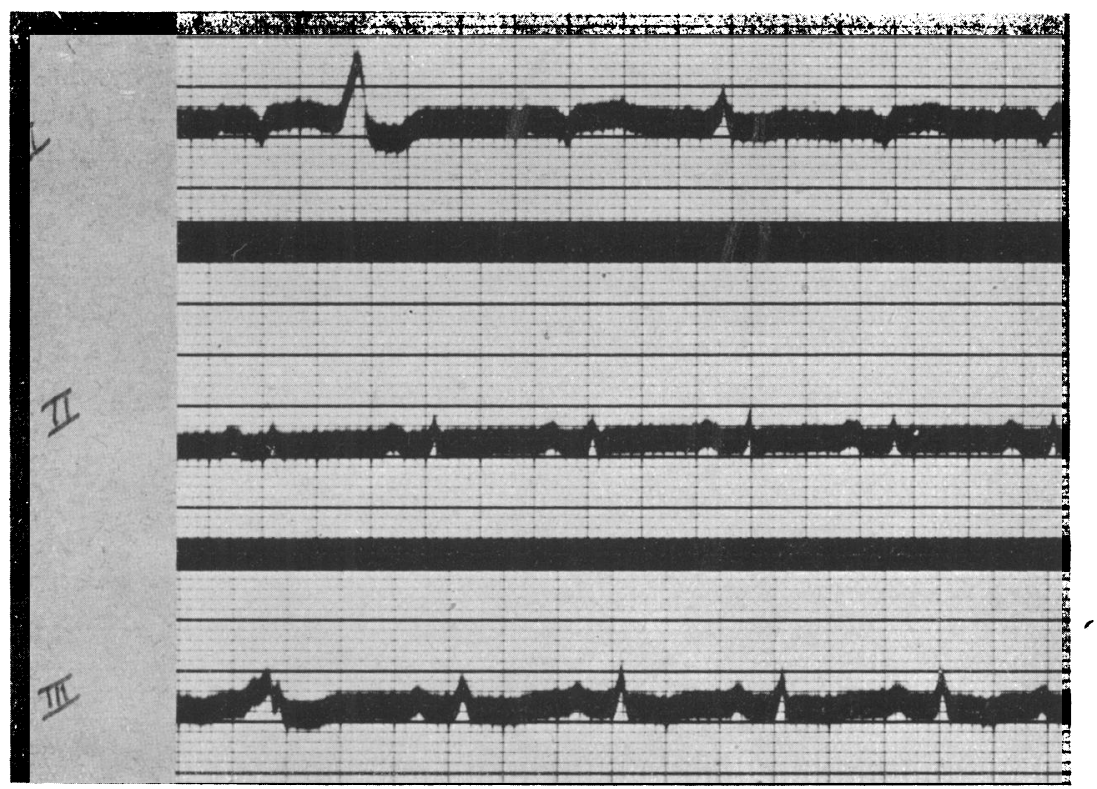

FIG. 5.-Case 2 (6i5/48). Electrocardiogram showing further lowering of voltage.

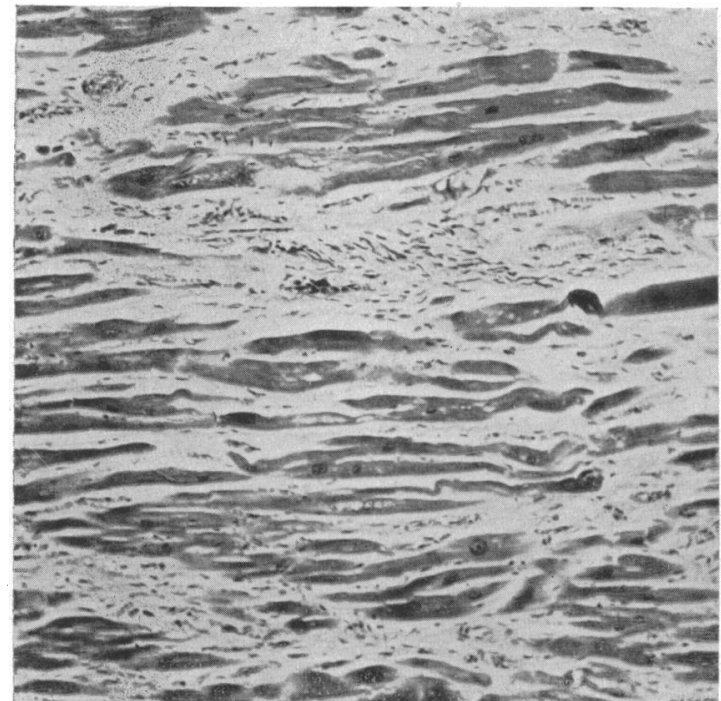

FIG. 6.-Case 2. Myocardium of ventricle, $\times 90$. Stained with hæmatin and eosin.

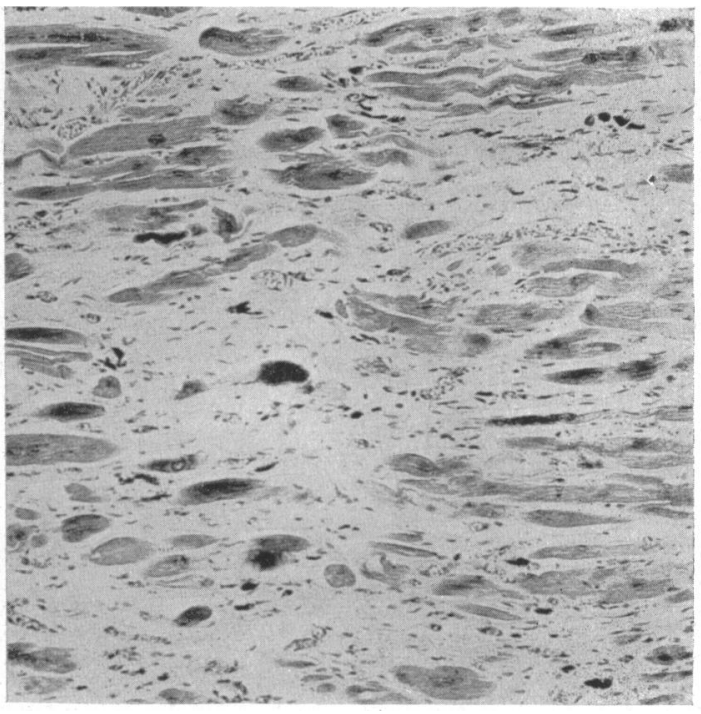

FIG. 7.-Case 2. Myocardium of ventricle, $\times 90$. Stained for iron. 


\section{Discussion}

It is evident from the cases quoted and from our own experience that the cardiac manifestations of hæmochromatosis are not negligible and may even dominate the clinical picture. It is only in recent years that attention has been directed to the changes in the heart in this disease, and up to 1935 electrocardiographic observations had been made in only eight cases (Sheldon, 1935). It is consequently impossible to determine in what proportion of cases of hæmochromatosis clinical evidence of heart damage would be found while the patient is still alive. Recent publications suggest that this must be quite frequent and in all cases in which there was evidence of heart disease during life, necropsy showed extensive changes in the heart muscle. These changes seem to us to be an adequate explanation of the heart failure and do not justify the introduction of any endocrine factor. In particular the cardiac enlargement and the frequency of arrhythmias and of death in congestive failure are very unlike the circulatory features of Addison's disease. The variability of the cardiac findings, including as they do arrhythmias, conduction defects, and $T$ wave changes, cardiac enlargement, and death in congestive failure seem to us to point to extensive damage to the heart muscle and all reports agree that there is no coronary insufficiency adequate to account for the atrophy of muscle and replacement fibrosis that has been described. The occurrence of pain identical with that seen in coronary artery disease is striking and perplexing. We have no explanation to offer for this interesting feature. It is of incidental interest that in hæmochromatosis the muscle of the heart should be so severely infiltrated with pigment when voluntary and plain muscle are relatively free. Sheldon has speculated that since the striped muscles most frequently used are those in which such pigmentation as occurs is most readily found, there may be some relationship between activity and pigment deposition.

\section{SUMMARY}

Previously reported cases of cardiac involvement in hæmochromatosis are reviewed. Two cases are described in one of which there was cardiac pain and $T$ wave changes; in the other, death from congestive cardiac failure occurred with gross cardiac enlargement, electrocardiographic abnormalities, and severe hæmochromatosis of the myocardium.

It is felt that the explanation for the observed changes is most probably the deposition of pigment in the myocardium and not any endocrine factor.

Our thanks are due to Dr. C. N. Armstrong for permission to publish Case 2 and to Dr. I. Rannie for his report of the necropsy of this case.

\section{REFERENCES}

Althausen, T. L., and Kerr, W. J. (1933). Endrocrinology, 17, 621.

Blumer, G., and Nesbit, R. (1938). N. Eng. J. Med., 218, 295.

Cann, G. A. (1933). U.S. Nav. Med. Bull., 31, 305.

Darnall, J. R. (1935). Ann. intern. Med., 8, 1121.

de Gennes, L., Delarue, J., and de Vericourt, R. (1936). Presse Med., No. $20,377$.

Griffin, W. R., Nelson, H. G., and Seal, J. R. (1950). Amer. Heart J., 39, 904.

Horns, H. L. (1949). Amer. J. Med., 6, 272.

Maling, T. C., and Riley, G. (1937). N. Zealand med. J., 36, 314.

Murray Lyon, R. M. (1936). Brit. med. J., 1, 1297.

Oumansky, V., and Longuet, A. (1938). Presse Med., No. 21, 388.

Petit, D. W. (1945). Amer. Heart J., 29, 253.

Sheldon, J. H. (1935). Hamochromatosis. Oxford Univ. Press, passim.

Tucker, H. S., Lloyd, F. M., and Williams, J. P. (1948). Amer. Heart J., 35, 993. 